DOI: $10.12957 /$ demetra.2016.16717

\title{
Representações sociais, histórica e cultural da canja de galinha: estudo de fontes históricas e de fontes orais de uma população de idosos
}

\section{Social, historical and culture representations of chicken soup: study on historical sources and oral testimony of an elderly population}

\author{
Carmen Soares' \\ Irene Coutinho de Macedo² \\ 'Universidade de Coimbra, Faculdade de Letras, \\ Coordenação do mestrado "Alimentação: Fontes, \\ Cultura e Sociedade" e do mestrado "Estudos \\ Clássicos". Coimbra, Largo da Porta Férrea, \\ Portugal. \\ ${ }^{2}$ Centro Universitário Senac, Curso de \\ Bacharelado em Nutrição. São Paulo-SP, Brasil. \\ Correspondência / Corrrespondence \\ Irene Coutinho de Macedo \\ Centro Universitário Senac, Coordenadora do \\ curso de Bacharelado em Nutrição \\ Av. Eng Eusébio Stevaux, 823 , São Paulo-SP, \\ Brasil - CEP 04696-000 \\ E-mail : Irene.cmacedo@sp.senac.br
}

\section{Resumo}

Este estudo teve como objetivo investigar as representações sociais, histórica e cultural do consumo de canja de galinha em uma população de idosos. A investigação foi estruturada em pontos que contemplaram "fontes orais", "fontes escritas" e "articulação entre fontes orais e escritas". A investigação em fontes orais deu-se pela coleta de testemunhos entre a população idosa, através da metodologia de grupo focal. No que concerne às fontes escritas, buscaram-se textos de duas áreas do saber: medicina e culinária. Como resultados das fontes orais, participaram do grupo focal 11 idosos com média de idade de 69,09 anos, que identificaram os principais ingredientes da canja como frango, arroz e batata. Indicaram ainda seu consumo adequado para diversos estados de convalescença, no puerpério e em situações de necessidades de conforto. Dentre as fontes escritas consultadas, destacam-se alguns tratados hipocráticos do século $\mathrm{V}$ a.C sobre dietética e obras médicas portuguesas cronologicamente situadas entre os séculos XVI-XIX. A articulação entre as duas tipologias de fontes de investigação permitiu destacar três focos de reflexão: 1) a descrição da receita, a preservação dos principais ingredientes e adaptações da receita a diferentes culturas alimentares; 2) a identificação das suas propriedades terapêuticas, 3) sua pertinência sociocultural. Concluímos que a canja de galinha, ainda que com adaptações de preparo, constitui, entre a população de idosos estudada, um elemento agregador da comunidade e um recurso terapêutico em diversas situações requerentes de cuidados.

Palavras-chaves: Canja de Galinha; Patrimônio Alimentar; História da Alimentação; Brasil; Portugal. 


\section{Abstract}

This study focuses on the social, historical, and cultural representations of the chicken soup, with analyses based upon parameters that examine written sources, oral sources, and the intersection between oral and written sources. For oral sources, we collected personal testimonies from an elderly population utilizing the focus group methodology. Regarding written sources, we searched for texts in two content areas: medicine and culinary. The focus group was constituted by 11 elderly aged 69.09 years on average, who identified chicken, rice and potato as the main chicken soup ingredients. They also said that it was the convenient meal for convalescent phases, during the puerperium and in contexts of emotional sufferance. The written sources studied were mainly some Hippocratic treatises on dietetics (5th century BC) and other Portuguese medical works published between the 16th and 19th centuries. The comparative analysis between the written and oral sources allowed us to focus our research on three subjects: 1) The recipe's description and the maintenance, since its historical appearance to nowadays, of main ingredients, although some "novelties" occurred, imposed by cultural adaptation; 2) The acknowledgement of its therapeutic qualities; 3) Its socio-cultural relevance. We conclude that, although with slightly circumstantial adaptations, the recipe of chicken soup represents to the eyes of the elderly group inquired a stimulus for the establishment of bounds inside a community and continues to be considered a therapeutic resource, like it was when it first appeared in the 16th century.

Key words: Chicken Soup; Culinary Heritage; Culinary History; Brazil; Portugal.

\section{INTRODUÇÃO}

Este estudo resulta de uma parceria de investigação pouco usual nos meios acadêmicos e profissionais, mas da qual julga-se poder resultar uma reflexão mais completa sobre um dos muitos elementos constituintes do patrimônio alimentar luso-brasileiro: a canja de galinha. As autoras da pesquisa, ao estabelecerem um diálogo entre as áreas científicas da sua formação - a história e literatura, por um lado, e a nutrição, pelo outro - pretendem demonstrar como o resultado dessa aproximação se traduz num conhecimento mais fidedigno de costumes e práticas alimentares tidas como definidoras de uma identidade, tanto em Portugal como no Brasil, com raízes num passado cujas origens estão perdidas, para a maioria dos seus herdeiros, num tempo e espaço de contornos mal definidos. 
O objetivo estabelecido foi investigar as representações sociais, histórica e cultural do consumo de canja de galinha em uma população de idosos, verificando em que medida a receita da canja de galinha e as motivações para o consumo refletem ideias que derivam de uma corrente de transmissão cultural e também de escritos médicos e receitas.

Assim, a investigação tem como base as seguintes premissas:

a) por ser considerado um prato tradicional, isto é, com uma história, recorremos à consulta de fontes orais e escritas; neste domínio, impôs-se definir quer o grupo de indivíduos a inquirir, quer o corpus de textos capazes de conter informação histórica sobre a matéria;

b) proceder à pesquisa das vertentes histórica e cultural de acordo com as metodologias próprias a cada ciência;

c) partindo dos resultados da pesquisa feita com o grupo focal definido, verificar a articulação entre as fontes históricas e suas origens que podem fazer recuar não apenas às gerações mais próximas, de que os inquiridos guardam uma memória pessoal, mas também a escritos médicos e receitas de um passado secular e até milenar, só recuperável através da memória indireta facultada pela escrita.

Divide-se, por conseguinte, a análise em três pontos, de acordo com as premissas acabadas de enunciar: investigação das fontes orais; investigação das fontes escritas e articulação entre fontes orais e escritas.

\section{Investigação das fontes orais}

No caso da abordagem dos testemunhos orais, através da técnica de grupos focais de discussão, buscou-se levantar conhecimentos e atitudes sobre o consumo de canja de galinha e suas representações sociais e culturais em uma população de idosos. Para Garcia, ${ }^{1}$ o estudo das representações sociais deve considerar os elementos da realidade, os conceitos, as teorias e as práticas que são submetidos a uma reconstituição com base nas informações colhidas e na bagagem histórica (social e pessoal) do sujeito.

A técnica de grupo focal, que consiste na formação de grupos de discussão que dialogam sobre um tema em particular a partir de estímulos apropriados para o debate, foi escolhida por ser indicada como uma estratégia que permite identificar conceitos, crenças, percepções, expectativas, motivações e necessidades sem provocar, a priori, mudanças nos sujeitos da pesquisa..$^{2-4}$ Para sua operacionalização, viabilizou-se a formação de um ambiente apropriado para um debate informal entre os participantes, permitindo compartilhar sentimentos, entendimentos, experiências e conceitos do tema estudado. 
As discussões do grupo focal foram conduzidas por um facilitador, que seguiu um questionário semiestruturado. Neste, constavam perguntas sobre a receita para o preparo da canja de galinha, em quais situações de doença o consumo de canja de galinha era indicado e os motivos dessa recomendação. O encontro teve duração de 40 minutos, quando foi favorecida a participação de todos os membros do grupo.

Com a autorização dos participantes, as falas foram gravadas em meio digital e posteriormente transcritas para análise, sendo identificados os principais núcleos de sentido presentes nos discursos.

Em conformidade com a Resolução n ${ }^{\circ}$ 196/96 sobre pesquisa envolvendo seres humanos, do Conselho Nacional de Saúde, foram garantidos o sigilo e o anonimato aos participantes, sendo a adesão estritamente voluntária, mediante aceitação e a assinatura de Termo de Consentimento Livre e Esclarecido. Estando a pesquisa vinculada ao projeto de pesquisa "Perfil alimentar e antropométrico da clínica de nutrição do Centro Universitário Senac", foi aprovada pelo Comitê Interno de Ética em Pesquisa do Centro Universitário Senac, sob o parecer $\mathrm{n}^{\circ}$ 104.03.12.

Por se tratar de uma receita que hoje é considerada da cozinha tradicional, decidiu-se proceder à coleta de testemunhos orais entre a população idosa. Segundo Freitas \& Costa, ${ }^{5}$ a atual facilidade de comunicação intercultural, os avanços tecnológicos e a globalização podem interferir na preservação da identidade cultural. Assim, deve-se valorizar a oralidade do idoso, visto que reflete a memória construída pelas representações sociais expressas pelas crenças, mitos e saberes populares.

A Organização Mundial da Saúde classifica cronologicamente como idosos as pessoas com mais de 65 anos de idade em países desenvolvidos e com mais de 60 anos de idade em países em desenvolvimento. ${ }^{6}$ No Brasil, segundo o Estatuto Nacional do Idoso, são idosos os indivíduos com 60 anos ou mais. ${ }^{7}$

A população de estudo foi composta por 11 (onze) idosos atendidos em uma clínica escola de nutrição que se reunia semanalmente no município de São Paulo (SP), sendo dez do gênero feminino e um do gênero masculino, com média de idade de 69,09 anos e desvio-padrão \pm 8,09. Sobre a origem geográfica, apenas um dos idosos é natural de São Paulo, capital. Os demais são provenientes principalmente de municípios do interior dos estados de São Paulo, Minas Gerais e Bahia. Dois idosos relataram ser provenientes de imigração portuguesa e uma idosa de origem eslovena. Todos os demais relataram ser do Brasil ou desconhecem a imigração de origem. Esse dado pode ser explicado pelos movimentos migratórios que aconteceram no século XX, especialmente na década de 70, quando houve grande deslocamento de pessoas dos estados brasileiros e das regiões interioranas para os grandes centros urbanos, em particular para a cidade de São Paulo. ${ }^{8}$ 


\section{Investigação de fontes escritas}

No que se refere às fontes históricas, buscaram-se textos escritos de duas áreas do saber, distintas na dimensão em que abordam a alimentação, mas complementares: a medicina e a culinária. Aliás, aquela, nos seus primórdios (dos tratados hipocráticos do século $\mathrm{V}$ a.C.), reconhecia à ingestão de alimentos, a par do exercício físico, o papel de promotores da saúde humana ${ }^{a}$ Daí fazer todo o sentido encontrar na literatura médica recomendações sobre as propriedades terapêuticas de alimentos e de determinados pratos, assim como também em manuscritos de conventos (que agregam "mezinhas" ou, em português do Brasil, "simpatias místicas" às receitas culinárias) e em livros de cozinha. Por se tratar de averiguar a "certidão de nascimento" da canja de galinha, recorre-se também à informação fornecida por vocabulários/dicionários dos séculos XVII a XX.

Considerando que o primeiro registro escrito do prato em questão teve lugar na obra do médico português Garcia da Orta (1500-1568), selecionaram-se obras cronologicamente situadas entre os séculos XVI a XIX, que circulavam, pelo menos no caso dos textos médicos, nos dois territórios lusófonos considerados. Além dos Colóquios dos Simples (1563) de Orta, ${ }^{9}$ médico de D. João III e do vicerei da Índia Martim Afonso de Sousa, serão tidos em conta a Âncora Medicinal (1721) de Henriques, ${ }^{10}$ médico de D. João V, o Tratado Completo de Chirurgia Obstreticia (1815) de Costa, ${ }^{11}$ dedicado a D. Pedro, Príncipe Regente do Reino Unido de Portugal, Brasil e Algarve (futuro rei D. Pedro IV de Portugal e I do Brasil) e os Elementos de Hygiene, ou Dictames Theoreticos, e Practicos para conservar a Saude e prolongar a Vida (1814) de Franco, ${ }^{12}$ natural de Paracutú (Minas Gerais), médico da arquiduquesa da Aústria, Maria Leopoldina, esposa do que viria a ser o monarca "Libertador" do Brasil.

Na categoria de "Livros de Culinária”, observou-se um manuscrito conventual, cujo receituário remonta ao século XVI, logo bastante próximo da obra de Garcia da Orta, o no 142 do Arquivo Distrital de Braga (ADB), e o Cozinheiro Moderno ou Nova Arte de Cozinhar (1780) de Rigaud, ${ }^{13}$ cozinheiro de várias cortes europeias, além da portuguesa. No caso desta literatura, o enfoque da análise recai sobre os conteúdos que denunciam a consciência de uma diferenciação de receituário de acordo com a saúde (ou falta dela) dos consumidores.

As fontes escritas não foram tratadas sob uma perspectiva endógena, ou seja, fechada sobre os contextos histórico-culturais de cada uma, mas de um ponto de vista dialógico, sincrônico e diacrônico para a compreensão das representações sociais no consumo da canja de galinha.

Queremos com isto esclarecer que buscamos detectar padrões comuns e/ou complementares de informação entre as fontes e, dentro do que são os limites da razoabilidade da especulação própria da análise histórica, propor leituras que aclarem o processo de construção e transmissão

${ }^{a}$ Cf. Da dieta: "Realmente alimentos e exercícios físicos têm dinâmicas opostas, mas contribuem ambos para a saúde: enquanto os exercícios produzem a destruição dos excedentes, os alimentos e as bebidas repõem as perdas" (trad. Carmen Soares). 
cultural, de geração em geração, de um ideário sobre a canja de galinha, hoje bem vivo, enquanto patrimônio identitário luso-brasileiro.

\section{Articulação entre as fontes orais e as escritas}

A informação recolhida do estudo comparativo entre fontes escritas e orais permitiu-nos destacar três focos principais de reflexão, que se inter-relacionam: a descrição da receita, a identificação de suas propriedades terapêuticas e sua pertinência sócio-cultural.

\section{Receita para o preparo da canja de galinha}

O grupo focal relatou conhecer e haver consumido a canja de galinha em diversas situações da vida. Os ingredientes mais comumente incluídos no preparo são o frango, o arroz e batata. Os ingredientes são bem cozidos e acrescidos de temperos. Entende-se ser esta a receita básica preparada por todos. No entanto, divergências sobre os cortes de frango a serem utilizados, bem como o tempero e a adição de outras hortaliças são observadas nas falas dos interlocutores.

[...] franguinho, pescoço, asa, costelinha. Tempero normal e um pouquinho de tomate para não ficar muito branca e mais temperinhos [...] e manteiga de garrafa.

[...] a gente colocava de tudo na canja-miúdos, pescoço, asa. O peito de frango não. Deixa muito seco...

[...] couve cortada fininha também... ah... também o que tiver de legumes a gente coloca.... e banha da galinha também.

Dentre os elementos essenciais da canja estão o frango, o arroz e a batata. Os demais são acrescentados como reflexo das adaptações culturais e referidos como importantes para agregar sabor e melhorar a aparência e textura, tornando a preparação mais atrativa para o consumo.

Perante este "quadro" culinário, em que a base da receita tradicional de canja de galinha junta ao frango uma panóplia variada de legumes disponíveis, vejamos o que nos revelam as fontes escritas sobre os preparos mais antigos, por forma a reconstituirmos as origens quinhentistas da canja. É no Colóquio 17 de Garcia da Orta, ${ }^{9}$ sobre a cólera (conhecida entre os Europeus por colirica passio e entre os Indianos por morxi), que nos deparamos com o que julgamos ser a explicação para reconhecermos na canja de galinha um prato nascido de uma fusão das cozinhas medicinais indiana e portuguesa.

Quando Orta, a pedido do seu interlocutor, o médico espanhol Ruano, esclarece quais eram as dietas alimentares distintas que os físicos indianos e os portugueses ministravam ao enfermo, torna-se bastante sugestiva a interpretação de que terá sido do cruzamento entre as duas prescrições alimentares terapêuticas que nasceu a canja, associada, desde a gênese, a fins medicinais. "Canje", termo indiano, é a denominação que os médicos indianos dão ao caldo resultante da cozedura de 
arroz, temperado com duas especiarias locais, a pimenta e os cominhos. Por seu turno, a prescrição tradicional dos médicos lusos contemplava, entre outros preparados, galinhas estufadas ou caldos de galinha. Como se lê:

$R V$. Como curã os fisicos da terra esta efermidade. OR. Dãlhe a beber agoa despresam darroz cõ pimta, e cominhos (a que chamã cãje) cautirizã lhe os pés como mãdei fazer a aquele fidalgo, (...) RV. E vos os purtugueses que lhe pondes ou que fazeis. OR. Damos lhe a comer perdizes e galĩhas estiladas ou çumo delas tãbẽ lhe damos toradas de vinho cõ canela posto que estas cousas qẽtes eu nã uso muito nos comeres se nã pastas pola parte de fora. (Colóquio 17, fólio 74 verso).

O próprio Orta ${ }^{9}$ descreveu, antes (no fólio 73, verso), o que se pode entender por receita médica de "estilar" (em linguagem moderna "estufar") galinha:

[...] açerqua do comer da casa estilem hũa galinha gorda tirãdolhe primeiro agordura que tem, e deitem lhe dentro hũas talhadas de marmelos, e se os não acharem frescos sejam de cõserva lavados primeiro cõ vinho brãco, e lancenlhe hũa pouca dagoa de canella, e rosada, e coral, e ouro, e posto que ho doutor que presente esta saiba milhor istoque todos, pera ho que se deve fazer, elle meda a mão a iso como homẽ espremẽtado nesta terra, e porq̃ ele esta presente diguo que milhor fora perdiz ou dormuz ou da terra, ou guallo, ou gallinha, de mato, mas em quanto se isso não acha podẽ fazer ho que dise.

Conforme poderemos perceber através da comparação dessa receita de galinha estufada com outras duas, inclusas no manuscrito ADB 142 (contendo a indicação de que são destinadas a doentes (receita 52 de "Galinha estilada" e receita 53 de "Caldo muito esforçado”, p. 166-169), ${ }^{14}$ percebemos que a base do preparado é cozer lentamente uma galinha (inteira ou desfeita em pedaços), numa panela vidrada e barrada a tampa com massa ${ }^{\mathrm{b}}$, por um longo período de tempo (entre 3 a 6 horas), juntamente com água (simples ou $\operatorname{aromatizada}^{c}$ ) e temperos variados (sal, ervas aromáticas, especiarias, açúcar ou azedo ${ }^{\mathrm{d}}$ ). $\mathrm{O}$ reforço medicinal da receita vem da junção de substâncias prescritas pelo físico. Neste domínio, o escrito médico e o manuscrito de cozinha (receita 53 de "Caldo muito esforçado") ${ }^{14}$ têm em comum o coral e o ouro. ${ }^{15}$

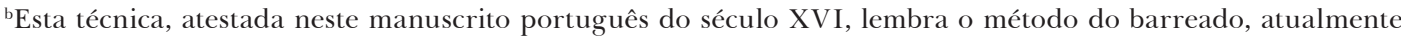
ainda vivo na cozinha tradicional paranense e leva-nos a reconhecer nela mais um elemento patrimonial alimentar comum a Portugal e ao Brasil.

${ }^{c} N a$ receita 53 indica-se a água rosada, ao passo que no Colóquio 17, além desta, menciona-se também a água de canela. A água rosada obtinha-se da adição de pétalas de rosa esmagadas à água e é uma presença muito constante na cozinha e botica medievais e da época moderna. Que se tratava de um "aroma" elementar do gosto dos colonos portugueses, de que importa garantir a continuidade nas terras brasílicas recentemente descobertas, atesta-o a alusão expressa ao cultivo de rosas (particularmente as de Alexandria) em Piratininga/São Paulo e no Rio de Janeiro - feitas por dois autores do último quartel de Quinhentos: Gabriel Soares de Sousa (cap. LXII da Notícia do Brasil) e Fernão Cardim (capítulo "Dos animais, árvores, ervas, que vieram de Portugal e se dão no Brasil" da obra Do clima e terra do Brasil e de algumas cousas notáveis que se acham na terra como no mar).

${ }^{\mathrm{d}}$ Repare-se que na categoria dos acres colocamos as limas mencionadas na receita 53 do ADB 142, bem como os marmelos, referidos por Garcia da Orta no Colóquio 17, fólio 73 verso.
} 
Num relato de natureza bastante diversa, a literatura de viagens, também do século XVI, a História Trágico-marítima de Manuel Godinho Cardoso, em relato do naufrágio da nau de Santiago (1585), confirma-se a inclusão da canja (de arroz ou milho, variante feita com o cereal vindo das Américas para a Europa por ocasião das navegações quinhentistas) na categoria da alimentação medicinal, uma vez que vem elencada entre as "mezinhas" disponíveis à época (p. 55). ${ }^{16}$

Em suma, antes de chegarem à Índia e conhecerem a “canje”, os portugueses já transportavam na sua bagagem cultural culinária e médica elementos que naturalmente se combinaram com um universo novo, mas não completamente estranho. No fundo, deixar cozer até se desfazerem os ingredientes é um denominador comum à tradição do caldo grosso de arroz condimentado e do caldo de galinha desfeita. Por outro lado, a carne de galinha, por ser reconhecida de forma generalizada, nos tratados médicos que nos chegaram, como uma das carnes mais aconselháveis para qualquer estado físico, não surpreende que se tenha imposto na preparação de um prato de reconhecidas propriedades terapêuticas, como desenvolveremos mais adiante neste estudo.

Saber quando é que a canja passou a ser entendida, como hoje, como um cozido que leva galinha e arroz não é tarefa fácil. Na verdade, se considerarmos os dicionários de língua portuguesa, verificamos que no século XVII, o vocábulo continuou a manter o seu sentido original de caldo de arroz desfeito, conforme atesta o Thesouro da lingua portugueza de Pereira, ${ }^{17}$ que define o termo "canja”, em latim, da seguinte maneira: "pulmentum Indicum ex oriza" ("caldo de arroz à maneira da Índia”). Em duas obras dicionarísticas do século seguinte, o Vocabulario Portuguez E Latino de Raphael Bluteau ${ }^{18}$ e o Diccionario da lingua portugueza de Antonio de Moraes Silva, ${ }^{19}$ o sentido se manteve. Na primeira ${ }^{18}$ (vol. I, p. 104), deparamos com o verbete:

CANJA. Arroz cozido sem sal, muito delido, ficando a agua muito grossa, sem se enxergar bago de arroz; bebida, que se dá para engrossar o estillicidio. Decocta sine sale, Ė deliquata oryza, ae. Fem.

Na mesma obra, no suplemento, reaparece a referência a canja, agora definida tanto como "agoa do arroz" (vol. IX, p. 192), como "canudo", referindo-se ao utensílio usado para administrar a bebida aos enfermos.

No Diccionario (p. 337) $)^{19}$ confirmam-se ambos os sentidos presentes no Vocabulário de Bluteau, ${ }^{18}$ cf::

CANJA, s.f.t. da As. Arroz cozido até fazer um caldo grosso: Couto, 10. 8. 3. Arroz de fazião canjas, que são papas. § Canudo pelo qual se dá este caldo aos doentes.

Foi durante o século XIX, mais propriamente por volta do último quartel, que as fontes escritas confirmam que já se instalara plenamente a fusão luso-indiana resultante na receita de "canja de galinha”. Todavia, fruto ou não do conservadorismo próprio do registro dos dicionários, vemos no Diccionario da Lingua Brasileira de Pinto, ${ }^{20}$ datado da primeira metade dessa centúria (1832), ainda com acepção tradicional do prato, aliás, bastante próxima (quase uma cópia) da definição 
de Silva, ${ }^{19}$ acabada de citar. O autor brasileiro apresenta o seguinte verbete: "Canja, s. f. Na Asia caldo grosso de arroz bem cozido. O canudo por onde se da ao doente este caldo".

No entanto, em finais desse século (1881), o Diccionario contemporaneo da lingua portugueza de Francisco Júlio Caldas Aulete ${ }^{21}$ já consagra plenamente o sentido tradicional que hoje a canja tem para a população portuguesa e brasileira, pois a definia como "caldo de gallinha com arroz" (p. 275).

Se retomarmos a informação transmitida pelos entrevistados sobre as alterações de preparado a que a canja foi sujeita ao longo da sua evolução histórica, deparamo-nos com a consciência de que, numa fase mais recuada no tempo, de que os vivos ainda guardam a memória, a receita original se fazia com esses dois produtos básicos da receita indiana (o arroz) e da portuguesa (a galinha). Disso nos dá conta a seguinte observação de um dos membros do grupo de idosos inquiridos: "Hoje eu faço mais com macarrão. Minha mãe fazia mais, e só com arroz"

Também no caso da canja consumida em Portugal, pela observação empírica, verifica-se, de um modo geral, esta substituição progressiva do arroz pelas massinhas. A memória gustativa das pessoas na casa dos 80 anos, pelo menos na região centro do país, identifica-se com canja de arroz mais do que de massa.

Ainda no âmbito do preparado da canja de galinha, importa sublinhar que aspectos como o paladar dos consumidores e os recursos alimentares de que dispõem condicionam a sua composição. Disso nos dão conta quer os testemunhos orais quer os escritos. Assim, observou-se uma alteração entre os ingredientes que compõe a canja nas diferentes gerações que perpassam os sujeitos da pesquisa: os pais, filhos e netos.

[...] hoje eles não gostam de comer os miúdos do frango. Querem só o peito de frango. O bom mesmo era com a galinha caipira.

[...] ah, hoje tem sopas novas: tem caldo verde, sopa de cebola, tem um monte [...] mistura um monte de legumes, põe folha, serve com pimenta [...] assim é bom que não enjoa.

De fato, desde os mais antigos escritos médicos que chegaram aos nossos dias (os tratados hipocráticos do século $\mathrm{V}$ a.C.), que se tem em linha de conta que a doença diminui o apetite. Daí que encontremos, à imagem do que se nota nas alusões dos testemunhos orais acabados de relatar, indicações de receitas alternativas, destinadas a agradar ao palato dos consumidores. Repare-se que Costa, ${ }^{11}$ no seu Tratado Completo de Chirurgia Obstreticia, em inícios do século XIX, capítulo LXXXIV ("Do regime que devem observar as paridas"), tem em consideração os gostos da parturiente, a ponto de admitir que os mesmos ditem a dieta alimentar que lhe deve ser ministrada. A ordem pela qual se elencam as carnes sugere que o carneiro era o animal eleito para a confecção dos caldos, podendo ser substituído por vaca ou galinha, que poderíamos classificar de segundas escolhas. Em terceiro lugar, e só na falta das três espécies anteriores, se admite, como derradeira 
escolha, o toucinho (i.e., a carne de porco). No entanto, como se percebe da leitura do trecho em questão, o toucinho é de tal forma desqualificado que se prefere substituir o caldo de carne por umas sopas de pão, cuja descrição as aparenta ao primeiro tipo de açorda que, ainda hoje em Portugal, se dá aos bebês:

Quando a parida não soffrer o cheiro dos caldos feitos de carneiro, sera indifferente faze-los de vaca ou galinha, e sómente na falta destas tres substancias, se poderão fazer de toucinho. Em tal urgencia poder-se-hão preferir as sopas com azeite, apenas de ovos dissolvidos em água, ou os ovos passados pela mesma (p. 239-240). ${ }^{11}$

Ou seja, o paladar, além da disponibilidade de produtos, pode determinar as alterações de receitas convencionais.

Na linha de pensamento de que o preparado pode sofrer alterações relacionadas com os meios ao dispor do confecionante, e voltando ao tema da nossa pesquisa, verificamos que, apesar do entendimento de a receita básica de canja ser composta por frango, arroz e batata, houve relato de uma idosa oriunda da Região Nordeste do Brasil de adaptação da canja com a utilização de carne de sol, na ausência da carne de frango.

Quando mamãe não queria matar o frango, ela fazia com carne de sol [...] cozinhava bem a carne desfiadinha, ai colocava tempero e ia mexendo, mexendo assim até ficar bem, bem gostosa

Segundo Maciel, ${ }^{22}$ a dinâmica de adaptações do conjunto de elementos relacionados à cozinha de uma região ou grupo segue caminhos diferentes dadas as suas condições históricas e culturais, particularmente em países colonizados que foram fortemente influenciados pelo deslocamento de todo um conjunto de práticas culturais alimentares. Os apontamentos das fontes orais, bem como os achados nas fontes históricas sobre a receita e o preparo da canja revelam esse processo de adaptação, que é dinâmico e está sujeito a constantes transformações.

\section{Indicações e motivações para o consumo de canja de galinha}

Comecemos pelas informações transmitidas pelo grupo focal. Os idosos relataram os motivos e as situações em que seria indicado o consumo da canja. Assim, foi possível distinguir quatro situações específicas: 1) no tratamento de doenças e na convalescença; 2) situações que requerem cuidar do indivíduo; 3) para puérperas; e 4) na prevenção contra doenças associadas ao frio.

O discurso mais frequente de indicação para o consumo de canja foi para o tratamento de doenças e cuidado com o indivíduo convalescente. Em algumas falas, percebe-se que o grupo agrega o cuidado com as puérperas e também com indivíduos com necessidades de cuidado específico, como estando todos em situação de doença; ou seja, classifica a mulher no período de pós-parto em condição de doença ou de fragilidade extrema. 
Sobre a indicação do consumo de canja no processo de recuperação da saúde, os discursos foram bastante uniformes quando da necessidade de uma dieta especial para a recuperação do convalescente, composta basicamente de sopa, especialmente a canja de galinha.

Minha vó dizia que toda vez que fica doente ou tem neném precisa comer canja.

Eu gosto muito de comer uma canja de galinha. Quando estou doente, então, é muito bom.

A canja foi descrita como uma preparação que deve ser indicada para o tratamento das mais diversas doenças, independentemente do grau de convalescença ou da origem das doenças, reconhecendo seu importante papel terapêutico na recuperação. Isso foi possível observar nos seguintes discursos:

Quais doenças? Ah, para todas. Naquela época tinha muito sarampo, problema no estômago, quando ganhava neném, quando alguém não está bem, anemia, doença forte, os próprios médicos diziam façam uma canja.

[...] criança doente, velho doente, criança congestionada... todo mundo comia canja.

Uma vez tive uma doença que saia sangue do corpo e tinha muita febre (varíola). Aí minha mãe mandava eu tomar banho e depois me dava canja bem quente para comer. Durante 40 dias fiquei comendo canja e fiquei boa, graças a Deus.

No fundo, à luz do senso comum, a canja de galinha assume contornos de panaceia universal de todos os males, até mesmo os da alma. Na verdade, foi relatada como sendo um alimento importante para a recuperação do indivíduo fragilizado - por exemplo, em situações de velório e tristeza pela perda de entes queridos.

Quando morria alguém, tinha velório, a gente juntava as mulheres, os ingredientes e preparava uma canja. Ai as pessoas comiam uma coisinha para não passar mal.

Maciel, ${ }^{23}$ ao estudar o binômio "cultura e alimentação", destacou a existência de uma alimentação culturalmente reconhecida como adequada para um velório, onde as pessoas que vêm prestar suas homenagens estão em condição de sentinela e deverão receber a oferta de comida e bebida, uma vez que poderão ter fome. O evento gera uma comensalidade não festiva, para a qual são estabelecidos códigos e padrões adequados para a alimentação na ocasião. A autora destaca um trecho de Dona Flor e seus dois maridos: "Escola de Culinária Sabor e Arte. Quando e o que servir em velório de defunto", no qual se observa a presença da canja de galinha, especialmente para as famílias de pessoas com mais recursos financeiros:

Se o velório, porém, for de categoria, dessas sentinelas de dinheiro a rodo, então se impõe uma xícara de chocolate à meia-noite, grosso e quente, ou uma canja gorda de galinha. E, para completar, bolinhos de bacalhau, frigideira, croquetes em geral, doces variados, frutas secas. Para beber, em sendo casa rica, além do café pode haver cerveja ou vinho, um copo tão-somente para acompanhar a canja e a frigideira. Jamais 
champagne, não se considera de bom tom (p. 4). ${ }^{24}$

Sobre o efeito terapêutico da canja, se confrontarmos estes dados com as fontes escritas médicas e culinárias, de imediato nos damos conta de que a fama da galinha como alimento recomendado para a cura de numerosas maleitas é secular e, em última instância, deriva da medicina hipocrática, pervivente nos princípios e ditames dos tratados médicos da Época Moderna. No texto grego $D a$ dieta, em capítulo consagrado às propriedades das aves (§47), grupo em que figura a galinha, já se admitia que, por comparação com a carne de bovinos, ovinos, caprinos e suínos, os voláteis têm a vantagem de apresentar uma carne mais magra. Ou seja, estamos perante um alimento que granjeou, na literatura subsequente, o reconhecimento de "alimento saudável”. Desse estatuto, que os textos médicos mais antigos lhe reconhecem, evocamos, do primeiro quartel do século XVIII, o capítulo VII da seção III da Âncora Medicinal de Henriques, ${ }^{10}$ trecho consagrado à galinha, que, nos seguintes termos, atesta o bom nome do produto:

Entre as aves tem a Gallinha o primeiro lugar porque he bom alimento, assim para os saõs, como para os doentes. [...] A Gallinha tem muitas virtudes medicinaes, e por isto os Antigos supersticiosamente a a consagraraõ a Esculapio; que naõ ha parte della; que naõ sirva de remedio, e se houvessemos de fazer mençã̃ de todos, só para isto era necessario hum volume (p. 91). ${ }^{14}$

Entre as partes do corpo a que pode advir benefício pelo consumo de galinha, o autor refere o cérebro (promove a inteligência, estimula a memória e combate as dores de cabeça), a visão (que apura), o aparelho reprodutor masculino (pois afirma que "fazia crecer a materia seminal"), os rins (ajuda a eliminar pedras e areias) e a voz (combate a rouquidão). Deste conjunto de maleitas, os problemas com as cordas vocais são uma doença que no receituário do manuscrito ADB 142 vem identificada no título da receita 144. De fato, o "Caldo muito substancial para pregadores" é feito de carne de galinha, enriquecido com ovos e vinho do melhor (p. 258-259). ${ }^{14}$

Também nos Elementos de Hygiene de Franco, ${ }^{12}$ cerca de um século mais tarde, no ponto I do $\$ 1$ ("Dos volateis domesticos mais familiares entre nós"), capítulo V da seção III, insiste-se no louvor não apenas da galinha, mas de todos os galináceos:

Estas aves em qualquer idade, e de qualquer sexo que sejão, são proveitosas; pois até os mesmos gallos velhos ministrão excellentes caldos, e gelea. Ellas nos dão hum alimento saudavel, de facil digestão, e restaurante, que convém em estado de saude, de molestia, e de convalescença. $(\text { p. 133) })^{12}$

A literatura culinária reflete igualmente esta ideia geral de a carne de galináceos ser um alimento que se deve preparar de formas distintas, ajustadas ao estado de saúde dos consumidores. Veja-se o que faz Rigaud, ${ }^{13}$ em finais do século XVIII, ao distinguir, no capítulo $\mathrm{X}$ ("Dos Frangos") o modo de prepara-los para os doentes (rubrica em que se referem os caldos, a que podem ser adicionadas ervas medicinais e fármacos) do preparo destinado às pessoas saudáveis (assados, de fricassé, de entrada, de chouriços, recheados, de marinada, 
entre outros) (p. 143-151). ${ }^{13}$ Aliás, no seguimento de uma longa tradição clássica e medieval, onde as "mezinhas" convivem com as receitas para pessoas com saúde, o mestre cozinheiro, no capítulo XVII ("Dos caldos, e substâncias [...] para várias enfermidades, segundo os melhores Médicos") refere os caldos para sopas (receitas em que entra a galinha, a par de muitas outras carnes) e para convalescentes. ${ }^{\mathrm{e}}$

Sobre o consumo de carnes, Ornellas ${ }^{25}$ relata que no Brasil Colônia as galinhas eram compradas para o suprimento aos doentes, sendo assim, um alimento que devia compor a dieta para recuperação do convalescente.

Estudo de Godoy, Lopes \& Garcia ${ }^{26}$ aponta que no início do século XX alguns hospitais como a Maternidade Campinas e Beneficência Portuguesa produzia grande parte dos alimentos no próprio espaço das instituições em hortas, pomares e galinheiros e tinha funcionários para depenar as galinhas. Essa observação pode evidenciar a relevância da carne de galinha na dieta dos pacientes hospitalizados.

Ao mesmo tempo que se admitem propriedades terapêuticas gerais à canja de galinha, nota-se a incidência de uma condição clínica específica em que à dieta em apreço vem reconhecido um lugar de destaque: o das mulheres no puerpério. Assim, no grupo focal, deparamo-nos com relatos de que a canja favorece o aumento da produção de leite materno e a recuperação da mulher categorizando o pós-parto como um período de doença. Cuidados especiais para a dieta da mulher no puerpério, tanto no preparo da canja quanto no cuidado com a escolha dos ingredientes especialmente o frango - foram relatados como fundamentais para a boa recuperação.

Minha mãe cuidava das mulheres que ganhavam neném e ela aproveitava a banha da galinha para ficar mais forte.

Minha vó fazia eu comer a canja por 40 dias. É, precisava comer 40 dias para ficar forte, pra dar leite [...] comi canjica e canja e meu filho mamou até cinco anos de idade.

Meu marido, quando soube que estava grávida fez uma reforma no galinheiro... era assim: dois andares. No andar de cima separou uns pintinhos... quando eu queria comer, mandava eu escolher um dos franguinhos de cima e aí fazia a canja.

Estudos realizados com diversos grupos de mulheres brasileiras indicam a existência da crença de que alguns alimentos, ao serem consumidos pela parturiente, têm um poder de aumentar

\footnotetext{
"Na receita intitulada "Caldo para convalescentes" (Rigaud 1780, p. 212-213), entre os ingredientes de carne, aparece um peito de capão e outro de galinha ou perdiz, assados, que serão pisados juntamente com pão ensopado e uma gema de ovo, a que se juntam um caldo quente de vitela e galinha, passa-se por uma peneira e aquece-se ao lume, mas antes de ferver retira-se do lume e bebe-se. Este preparado assemelha-se muito à receita 14 do manuscrito ADB 142 ("Ensopado de galinha”, cf. Barros, 2013, p. 126-127). Também no "Caldo para doentes, e para sãos" de Rigaud (1780, p. 206) a galinha figura como ingrediente obrigatório.
} 
a produção de leite e de recuperar o estado convalescente da puérpera, especialmente a canja de galinha. Este alimento é associado por conter uma composição forte, saudável e necessária à produção de leite saudável para o bebê. ${ }^{27-29}$

Estudo com mulheres identificou a crença de que a canja de galinha, além de ser considerada uma preparação leve, é também um alimento quente que seria importante para manter em equilíbrio a temperatura do corpo e que uma exposição à friagem poderia promover uma inversão do fluxo sanguíneo, podendo subir à cabeça e causar insanidade mental nas mulheres. Ademais, a galinha seria uma das poucas fontes de proteína animal permitida à dieta da nutriz, visto que a carne de porco e de alguns peixes é considerada reimosa. ${ }^{30}$

Este conjunto de testemunhos (a que devemos juntar os atrás referidos a propósito do preparado da canja) remete-nos para crenças sobre a qualidade nutritiva da carne de galinha. A ideia de que a gordura "fortalece" é um mito alimentar que os textos médicos procuraram combater, mas infrutiferamente, pois, passados pelo menos seis séculos (se remontarmos ao colóquio de Garcia da Orta: fólio 73 verso), ${ }^{9}$ uma parcela da população (rubrica em que se inserem os testemunhos orais recolhidos) continua a acreditar que só um caldo gordo de galinha confere propriedades curativas à canja. No seu tratado sobre obstetrícia, Costa ${ }^{11}$ aposta na dismitificação de algumas crenças, que, ao que pudemos apurar pela amostragem efetuada, ainda hoje não desapareceram por completo. Escreve o médico, em inícios do século XIX:

He hum erro acreditar que as galinhas pretas sejão preferiveis ás de outra côr, para fazer os caldos, e alimentar as paridas. Unicamente se deve procurar que sejão novas, e sãs, a fim de se digirirem melhor. Outro erro prejudicial consiste em terem os caldos muita gordura, pois esta substancia dos animaes he a mais tardia na digestão, de menos succos nutritivos, e que fazendo-se rançosa he causa das piores acrimonias. (p. 239). ${ }^{11}$

Além da quantidade de matéria gorda, outro critério tido em conta para avaliar a boa qualidade da galinha, quer pelos médicos quer pelos leigos, é a idade dos animais e a sua robustez. Reparese que uma das idosas inquiridas esclareceu que, no período de gestação, lhe estavam reservados galinácios selecionados. Criados à parte, seriam abatidos quando a sua carne ainda era tenra (daí serem chamados de "franguinhos"). Esta é uma crença popular que, ao contrário da relativa ao nível de gordura, concorda com as recomendações médicas. Tal como Costa ${ }^{11}$ (como acabámos de

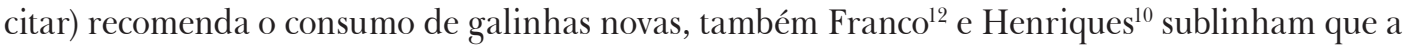
qualidade está na robustez e juventude dos animais. Enquanto o primeiro ${ }^{12}$ refere:

As gallinhas até dous annos, quando muito, bem alimentadas são as melhores pelo tenro das suas carnes. Os frangos sómente são bons até hum anno, também quando muito; porque de então por diante a sua carne torna-se sucessivamente dura, e secca. (p.133).

O segundo, ${ }^{10}$ cerca de um século antes, já afirmava:

O que se ha de entender das Gallinhas bem nutridas, e novas, que ainda naõ dem ovos. As velhas, são frias, e seccas, duras, e nervosas; e ainda que estejaõ gordas, naõ nutrem bem, saõ indegestas, e fazem mais danno, que utilidade (p. 91). 
Passados dois séculos, Cascudo ${ }^{31}$ aponta que a influência ao consumo de canja de galinha no Brasil é de origem portuguesa uma vez que a população negra africana não tinha por hábito consumir galináceos, pois estes eram considerados entes de sacrifício e não de alimentação regular.

A tradição antiga fazia consistir o resguardo em alimentação exclusiva de galinhas. Era costume português. Nos últimos meses da gravidez, guardavam, prudentemente, as galinhas do resguardo, do parto, da parida. Ficavam num galinheiro próximo, comendo milho, farinha estufada com água e sal, também defendidas de barulho e zoadeira para não "aperrear". A comida de galinha no estado puerperal era uma característica inevitável. Quando a capoeira se enchia, tinha o povo a denúncia positiva de que alguém devia "estar de criança" [...] (p.652). ${ }^{31}$

A canja foi, ainda, reconhecida por membros do grupo focal, como dieta necessária ao doente no ambiente hospitalar, mas referida como uma preparação não saborosa:

Quando ficava doente, os pacientes tinham que comer canja no hospital. Era sem sal, mas a canja era a dieta que davam para os doentes.

No parto da minha filha passei mal e depois não consegui comer. A única coisa que eu podia comer era uma canja cremosa mas eu não consegui comer, era ruim.

As pessoas não queriam comer outras comidas mas a canja elas aceitavam. Era mais fácil aceitar.

Embora não tenhamos procedido a um estudo da documentação sobre dieta hospitalar, a inclusão de caldos de galinha nesse receituário era uma prática comum, como já está atestada, entre outros, para o século XVII (ca. 1610), no Hospital Real de Todos os Santos, de Lisboa, ${ }^{32}$ e para os séculos XVIII-XIX, em Coimbra ${ }^{\mathrm{f}}{ }^{33,34}$ No Brasil, estudos apontam que sopas e canjas são referidas como preparações indicadas aos pacientes e constantemente adjetivadas como dieta hospitalar leve, fraca, comida de hospital..$^{35,36}$

Enquanto alimento com propriedades preventivas contra doenças, repare-se que o grupo interrogado refere que, nos dias atuais, o consumo de canja é mais indicado para aquecer dias frios e para evitar pegar gripe. Pode ser consumida em padarias e restaurantes no município de São Paulo, nos dias frios.

O consumo de alimento quente para manter o equilíbrio hermético em condições climáticas de baixa temperatura também caracteriza uma representação cultural, observada pelo equilíbrio

${ }^{\mathrm{f} C o m o}$ refere a historiadora Maria Antónia Lopes, com base no estudo das fontes para o conhecimento da alimentação dos doentes e funcionários dos hospitais de Coimbra (entre meados do século XVIII e meados do século XIX), não podemos esquecer que os hospitais, nas suas origens, eram uma instituição de assistência a indigentes, na medida em que a ele recorriam apenas aqueles que não tinham posses para pagar a visita domiciliária de um médico, bem como custear uma dieta de fortalecimento, à base das “imprescindíveis galinhas” (Lopes, 2012, 147). A galinha estava reservada aos doentes mais debilitados, ou seja aqueles cujo organismo não suportava alimentos mais "pesados" (idem, p. 163), e tinha o estatuto de alimento de luxo (idem, p. 157). 
entre dieta e temperatura da estação. Na linha da tratadística médica hipocrática, pervivente desde a Antiguidade aos nossos dias, recomenda-se a ingestão de alimentos à temperatura contrária à do ambiente. ${ }^{37} \mathrm{Ou}$ seja, a canja de galinha, por ser quente, aquece o organismo e ajuda a combater as doenças geralmente associadas ao frio.

No geral, observou-se entre os membros do grupo focal um grau de descontentamento pela falta de reconhecimento do efeito terapêutico da canja nos dias de hoje, sendo excluída das dietas para a recuperação das diversas doenças e também como componente de uma dieta saudável:

Hoje desvalorizaram o efeito da alimentação. Antigamente as pessoas evitavam comer alimentos que provocavam gases como feijão, mas hoje eles já liberam para comer de tudo. A mulher acaba de ganhar o neném e já pode comer de tudo.

O primeiro prato do dia era uma sopa ou uma canja, depois a gente jantava. Hoje em dia isso mudou.

Hoje eu faço ainda mas as pessoas não estão acreditando muito.

Deste conjunto de comentários, importa atentarmos para o que as fontes históricas escritas nos permitem averiguar sobre o lugar que a canja tradicionalmente ocupava nos menus diários. Para isso recorremos às ementas elaboradas para a Casa Real portuguesa em finais do século XIX ${ }^{38}$ Aí encontramos a distinção entre duas refeições principais ao dia: o almoço, tomado de manhã; e o jantar, geralmente às 6 horas da tarde, podendo passar para as 8 horas da noite, em ocasiões festivas. Destacamos a presença da "canja de gallinha" no menu de almoço do dia 7 de julho de 1880, destinado a suas Altezas, os filhos dos soberanos, D. Luís e D. Maria Pia. Por ser considerada uma sopa mais leve, ao que tudo indica, é que se reservava a canja para a primeira refeição do dia, contemplando o menu do jantar congêneres mais pesadas, como sopas de legumes e de massas alimentícias, entre outras. Curiosamente, a presença da canja, segundo o testemunho do Professor Thomaz de Mello Breyner, ${ }^{39}$ na mesa real dos Braganças em geral, deve estar, ainda assim, relacionada com preocupações de saúde - ou seja, inseria-se nos cuidados dietéticos rotineiros dos monarcas, seus familiares e particulares que privavam da casa real. Disso nos damos conta através da seguinte referência:

Todos os dias vinha à mesa real uma terrina de canja e uma travessa com galinha cozida e arroz branco. Sua Magestade comia a sua dieta especial e mais os jantares das outras pessoas. (p.222). ${ }^{39}$

É interessante notar que, mesmo contemporaneamente, as interpretações do vulgo em questões de valor nutritivo da canja variam entre dois extremos. Por um lado, tal como sugerem as diversas fontes históricas que colocam a tônica no consumo da galinha sem gordura, o prato pode ser denominado de "leve". Por outro, quando se enfatizam suas propriedades terapêuticas na recuperação de forças, ele ganha contornos de "alimento forte". Assim, em alguns momentos, os membros do grupo focal relatavam que a canja era um alimento forte pelo alto teor de nutrientes e pelo potencial de recuperar as energias do convalescente. Em outros momentos, os discursos 
apontaram a canja como um alimento leve, que poderia ser ofertado ao que estava sem condições de consumir uma alimentação completa e que não "ofenderia" o organismo do indivíduo debilitado.

As representações sociais sobre a canja de galinha como alimento com funções terapêuticas para diferentes estados fisiológicos e patológicos foram observadas tanto nas fontes orais quanto nas escritas e devem ser pensadas a partir dos contextos socioculturais específicos nos quais os mesmos ocorrem. Assim, os cuidados com a saúde e com a doença devem ser entendidos sob a perspectiva antropológica:

[...] quando se deparar com culturas diferentes, não se faça julgamentos de valor tomados com base no próprio sistema cultural, passando a olhar as outras culturas segundo seus próprios valores e conhecimentos - através dos quais expressam visão de mundo própria que orienta suas práticas, conhecimentos e atitudes (p.177). ${ }^{40}$

Outro contexto sociocultural em que a canja de galinha se destaca, de acordo com o testemunho dos idosos inquiridos, é o da festa. Na verdade, também foi relatada a possibilidade de confraternização e reuniões em que era oferecida canja como justificativa para o ajuntamento:

Minha vizinha fazia uma caldeirada de canja e chamava os vizinhos... era muito bom.

Neste caso, a canja foi o elemento motivacional para o "comer junto", reforçando a coesão e formação de identidade do grupo. Maciel ${ }^{23}$ destaca bem essa importância da partilha do alimento, da comensalidade, sendo o ato de se alimentar um acontecimento social por excelência.

\section{Considerações Finais}

A canja é reconhecida como um recurso terapêutico em diversas situações de doença e também para a recuperação de indivíduos mais fragilizados, com especial atenção para as mulheres no puerpério. Os aspectos nutritivos da preparação, consistência da dieta, restrições alimentares e necessidades nutricionais específicas tornam-se, nos testemunhos orais inquiridos, secundários à representação cultural que é atribuída à canja de galinha. As fontes consultadas para reconstituir a história da canja de galinha indiciam seu estatuto de prato de fusão indoportuguesa, sujeita a evoluções decorrentes do passar dos séculos e dos contextos socioculturais em que se implanta.

Não obstante, as transformações que a receita foi sofrendo, desde o século XVI (altura em que canja e caldos de galinha estão registradas como realidades distintas, partilhando ambas as receitas de propriedades curativas) ao século XIX (em que nos deparamos com as primeiras ocorrências da designação "canja de galinha"), há um denominador comum a toda essa evolução diacrônica e que ainda hoje confere ao preparado lugar único na cultura popular brasileira e portuguesa: ser considerado alimento com propriedades terapêuticas. 
Quanto aos agentes sociais responsáveis pela transmissão da receita, a entrevista feita ao grupo focal permitiu concluir que estes não diferem das mencionadas ou implícitas nas fontes escritas. Percebe-se que são as pessoas próximas que indicam o consumo da canja, forma de preparo e até métodos para criação do galináceo que comporá a canja. Os inquiridos revelaram que o aprendizado sobre o efeito terapêutico da canja lhes foi indicado por pessoas próximas à família, como mãe, tia, avó, sogra, vizinhos e também profissionais da saúde, especialmente o médico.

A canja é, assim, não só considerada um veículo de cuidado com a pessoa fragilizada, mas também como recurso para ajuntamento e confraternizações, à medida em que é oferecida tanto em velórios, como em encontros sociais. Constitui, por isso, um elemento agregador da comunidade em momentos fulcrais de expressão da solidariedade coletiva, o luto e a festa.

Em conclusão, se, nos dias atuais, a canja de galinha continua a fazer parte do patrimônio alimentar luso-brasileiro, sua sobrevivência se deve sobretudo ao respeito que esse prato merece, por ser sentido e vivido como uma tradição cultural ancestral, fundadora da história familiar e coletiva dos indivíduos, conforme evidenciaram as fontes escritas e as fontes orais da população idosa investigada.

Para identificar a preservação deste patrimônio nas últimas décadas, seria necessário ampliar a investigação para populações mais jovens, considerando os novos acessos à informação, os avanços tecnológicos e o intercâmbio cultural facilitado por novos meios de locomoção e comunicação.

\section{Referências}

1. Garcia RWD. Alimentação e saúde nas representações e práticas alimentares do comensal urbano. In: Canesqui AM, Garcia RWD, organizadores. Antropologia e nutrição: um diálogo possível. Rio de Janeiro: Editora Fiocruz; 2005. p. 211-225.

2. Iervolino SA, Pelicioni MCF. A utilização do grupo focal como metodologia qualitativa na promoção da saúde. Rev. Esc. Enf. USP 2001; 35(2):115-121.

3. Rabiee F. Focus-group interview and data analysis. Proceedings of the Nutrition Society 2004; 63(4):655-660.

4. Nogueira-Martins MCF, Bógus CM. Considerações sobre a metodologia qualitativa como recurso para o estudo das ações de humanização em saúde. Saúde e Sociedade 2004; 13(3):44-57.

5. Freitas AS, Costa MJ. A identidade social do idoso: memória e cultura popular [Internet]. Conexão UEPG 2011; 7(2):202-211. Disponível em: http://www.revistas2.uepg.br/index.php/conexao/article/ view/3718

6. World Health Organization. Active ageing: a police framework. Geneva: WHO; 2002.

7. Brasil. Lei No 10.741, de $1^{\circ}$ de outubro de 2003. Estatuto do Idoso. Diário Oficial da União, 03 de out. 2003. 
8. Baeninger R. Rotatividade migratória: um novo olhar para as migrações internas no Brasil. Rev. Inter. Mob. Hum. 2012; Ano XX(39):77-100.

9. Orta G. Coloquios dos simples, e drogas he cousas medicinais da Índia, e assi dalguas frutas achadas nella onde se tratam alguas cousas tocantes a mediçina, pratica, e outras cousas boas, pera saber. v. 1. [Internet]. Goa: Impresso por Joannes de Endem; 1563. Disponível em: www.bdalentejo.net/ bdaobra/bdadigital/Obra.aspx?ID=312.

10. Henriques FF. Âncora medicinal. Para conservar a vida com saúde. Os segredos da nutrição (1721). Coordenação de Pedro Vasconcelos. Sintra: Puma; 2000.

11. Costa J. Tratado completo de chirurgia obstreticia ou sciencia e arte de partos [Internet]. tomo I. Lisboa: Impressão Régia; 1815. Disponível em: http://archive.org/details/tratadocompletod01cost.

12. Franco FM. Elementos de hygiene, ou dictames theoreticos, e practicos para conservar a saude e prolongar a vida. parte I. Academia Real das Ciências, Lisboa: Typografia da Academia; 1814.

13. Rigaud L. Cozinheiro moderno, ou nova arte de cozinha, onde se ensina pelo methodo mais facil... / dado a luz por Lucas Rigaud.... - Lisboa: Offic. Patriarc. de Francisco Luiz Ameno; 1780. 508 p.

14. Barros AL. As receitas de cozinha de um frade português do séc. XVI. Coimbra: Imprensa da Universidade de Coimbra; 2013.

15. Highby GJ. Gold in medicine: a review of its use in the west before 1900. Gold Bull 1982; 15(4):130-140.

16. Brito BG. História Trágico-marítima, compilada por Bernardo Gomes de Brito com outras notícias de naufrágios (1585). 5 v. Tomo 2: Relação do naufrágio da nao de Santiago. No anno de 1585. E itinerário da gente que delle se salvou. Escrita por Manoel Godinho Cardozo e agora novamente acrescentada com mais algumas notícias. Lisboa. 1904.

17. Pereira B. Thesouro da lingua portugueza. Évora: Tipografia da Academia; 1697.

18. Bluteau R. Vocabulario portuguez \& latino. Coimbra: Colégio das Artes da Companhia de Jesus; 1716.

19. Silva AM. Diccionario da lingua portugueza recompilado dos vocabularios impressos. Lisboa: Typographia Lacerdina; 1789.

20. Pinto LMS. Diccionario da Lingua Brasileira. Ouro Preto: Typographia de Silva; 1832.

21. Aulete FJC. Diccionario contemporaneo da lingua portugueza. Feito sobre um plano inteiramente novo. Lisboa: Livraria; 1881.

22. Maciel ME. Identidade cultural e alimentação. In: Canesqui AM, Garcia RWD, organizadores. Antropologia e nutrição: um diálogo possível. Rio de Janeiro: Editora Fiocruz; 2005. p. 49-55.

23. Maciel ME. Cultura e alimentação ou o que têm a ver os macaquinhos de Koshima com BrillatSavarin?. Horizontes Antropológicos 2001; 7(16):145-56.

24. Amado J. Dona Flor e seus dois maridos. São Paulo: Martins; 1966.

25. Ornellas LH. Alimentação através dos tempos. Rio de Janeiro: Fename; 1978.

26. Godoy AM, Lopes DA, Garcia RWD. Transformações socioculturais da alimentação hospitalar. História, Ciências, Saúde-Manguinhos 2007; 14:1197-1215. 
27. Witt A. Alguns conhecimentos sobre nutrição ligados à gestação e ao puerpério. Rev. Saúde Pública 1971; 5:97-102.

28. Ichisato SMT, Shimo AKK. Aleitamento materno e as crenças alimentares. Rev. Latino-Am Enfermagem 2001; 9(5):70-76.

29. Marques ES, Cotta RMM, Priore SE. Mitos e crenças sobre o aleitamento materno. Ciência \& Saúde Coletiva 2011; 16(5):2461-2468.

30. Stefanello J, Nakano MAS, Gomes FA. Beliefs and taboos related to the care after delivery: their meaning for a women group. Acta Paul. Enferm 2008; 21(2):275-281.

31. Cascudo LC. História da alimentação no Brasil. São Paulo: Global; 2004.

32. Lemos M. História da medicina em Portugal. Doutrinas e Instituições. v. 1. $3^{\text {a }}$ ed. Lisboa: Dom Quixote-Ordem dos Médicos; 1991.

33. Lopes MA. Pobreza, assistência e controlo social em Coimbra (1750-1850). Viseu: Palimage; 2000.

34. Lopes MA. Os hospitais de Coimbra e a alimentação dos seus enfermos e funcionários (meados do séc. XVIII - meados do séc. XIX). In: Silva CG, organizador. História da saúde e das doenças. Lisboa: Colibri e Universidade de Lisboa; 2012. p. 147-164.

35. Maes G. A sopa no hospital: testemunho. In: Canesqui AM, Garcia RWD, organizadores. Antropologia e nutrição: um diálogo possível. Rio de Janeiro: Editora Fiocruz; 2005. p. 239-252.

36. Garcia RWD. A dieta hospitalar na perspectiva dos sujeitos envolvidos em sua produção e em seu planejamento. Rev. Nutr. 2006; 19(2):129-144.

37. Soares C. Matrizes clássicas gregas da história da dieta: contributos da tratadística hipocrática. In: Soares C, coordenação. Espaços do pensamento científico da antiguidade. Ciclo de Conferências \& Debates Interdisciplinares I. Coimbra: Imprensa da Universidade de Coimbra; 2013. p. 13-36.

38. Pereira AM. Mesa real. Dinastia de Bragança. Lisboa: Edições Inapa; 2000.

39. Breyner TM. Memórias do professor Thomaz de Mello Breyner, $4^{\circ}$ Conde de Mafra (1869-1880). Parceria António Pereira. Lisboa: 1930. 222 p.

40. Langdon EJ, Wiik FB. Antropologia, saúde e doença: uma introdução ao conceito de cultura aplicado às ciências da saúde. Rev. Latino-Am. Enfermagem 2010; 18(3):174-181. 